\title{
Health Promotion Model "Extracurricular" Approach of Reproductive Health among Early Adolescents
}

\author{
Lidia Hastuti $^{1}$, Wuriani ${ }^{2}$, Lilis Lestari ${ }^{3}$, Lestari Makmuriana ${ }^{4}$, Hidayah $^{5}$ \\ ${ }^{1}$ Department of Community Nursing, STIK Muhammadiyah Pontianak, Indonesia \\ 2,3,5 Department of Maternity and Child Nursing, STIK Muhammadiyah Pontianak, Indonesia \\ ${ }^{4}$ Department of Medical Surgical Nursing, STIK Muhammadiyah Pontianak, Indonesia
}

\section{Article Info}

Article history:

Received Feb 10, 2018

Revised Apr 11, 2018

Accepted Jun 6, 2018

\section{Keywords:}

Early adolescents

Extracurricular

Reproductive health

\begin{abstract}
The behavior to maintenance of reproductive organs, and self-adjustment on changes during puberty become its own problems on early adolescence (10-14 years old). True knowledge can improve reproductive health and prevent of free sex behavior end up with unsafe abortion even death in adolescence. School has a major role in shaping positive attitudes in children towards reproductive health at puberty. It is important to find and develop a program of reproductive health school-based in the form of "extracurricular" health reproductive in early adolescence (10-14 years old) not existed in Indonesia up to now. To find and design a model school-based health promotion programs in the form of "extracurricular" reproductive health that can be applied to the early adolescence in school. Qualitative research with a phenomenology approach, to explore models of reproductive health promotion programs in the early adolescence. The mining data was qualitative of focus group discussion (FGD) and in-depth interview. Participants in this research were 36 people of purposive sampling technique into account maximum variation sampling, and data analyze used the thematic analysis. The study results found a reproductive health promotion model school-base with extracurricular approach of reproductive health. The program is carried out outside school hours learning activities on reproductive health, with a study of the self-development, social, physical, sexual violence and the prevention of sexually transmitted infections. Program applied by using approach method and innovative media balance to age of adolescent's development and involve health workers, teachers and parents.
\end{abstract}

Copyright $@ 2018$ Institute of Advanced Engineering and Science. All rights reserved.

\section{Corresponding Author:}

Lidia Hastuti,

Department of Public Health and Community Nursing,

STIK Muhammadiyah Pontianak

Sungai Raya Dalam Street, Pontianak West Borneo, Indonesia.

Email: lidya_zain@yahoo.com

\section{INTRODUCTION}

The knowledge of reproductive health is a determinant of behavior toward the prevention of health problems. Adolescent behavior associated with unsafe sex is part of a lack of adolescents' knowledge, lack of access, skills and self-efficacy to negotiate [1]. Research proves that early sex education will prevent premarital pregnancy [2]. Surveys in adolescents aged 15-24 show the low knowledge of reproductive health, $21 \%$ of adolescent girls are unaware of changes in their selves when they are puberty phase, as many as $2.7 \%$ of girls and $14.2 \%$ of boys are known to have premarital sexual intercourse [3]. Approximately, 33.2\% of girls and $44.8 \%$ of boys agree on premarital sexual intercourse [4]. Adolescents sexual behavior are such as holding hands (male $60.1 \%$ and female 62\%), kissing (male 30.9\% and female 23.2\%) and petting (male 
$19.2 \%$ and female $6,5 \%$ ) [5]. $4 \%$ of adolescents aged 13-14 are reported to have had sexual intercourse and the percentage is rising along with the addition of teenagers 'age [6], even about $1 \%$ of boys and $4 \%$ of girls in Indonesia are reported to have had sexual intercourse before the age of 13 years, even some have sexual intercourse under 10 years [7].

The low knowledge of adolescents' results in premarital sexual behavior, premarital pregnancy, and abortion terminated in adolescent death, sexual assault and sexually transmitted diseases [8]. Strategic value in adolescents has resulted evidence base for creating policies and programs for adolescents [9]. Some evidence-based studies show, the effect is proven to be stronger when the target program was early adolescent [10]. Increasing adolescents' knowledge and forming positive attitudes and behaviors can prevent the occurrence of adolescent reproductive health problems such as free sex, sexually transmitted diseases, sexual violence, unwanted pregnancies, and unsafe abortion that can end in teenage deaths. Increasing the knowledge is more effective when addressed to students at the early stage of development and not yet sexually active.

Annual Technical Report 2011 stated that the effective reproductive health interventions on adolescents in developing countries are essential [11]. The consequences of unsafe sexual behavior are such as premarital pregnancy, abortion and sexually transmitted diseases including HIV infection [8]. Sexual health is currently prioritized in early adolescence [12] because it can prevent teenage pregnancy and sexually transmitted diseases [13]. Effective reproductive health interventions in adolescents in developing countries are essential [11].

School-based research by the SATZ Project on students of 12-14 years old is proven to increase adolescents' knowledge and positive attitudes toward reproductive health [10]. School curricula have not specifically included material about reproductive health. Limited reproductive health information is only obtained in science lessons. There is an urgent need to improve understanding about it through strategic research and to support governments in addressing youth groups. The results of the study will give a model of school-based reproductive health promotion program in the form of extracurricular that can be applied on early adolescence. Research on the development of school-based reproductive health programs with extracurricular approaches for early adolescents in primary school has not been conducted in a comprehensive way. It is important to find and develop models of school-based reproductive health promotion programs, in extracurricular form for early adolescents in school before they experience the puberty phase. Objective: To find and develop "School-based reproductive health promotion program model in the form of extracurricular reproductive health" aimed at early adolescents in school before experiencing puberty phase and can be a recommended program for policy makers as an alternative concept or model of school-based reproductive health programs in extracurricular form in early adolescence.

\section{RESEARCH METHOD}

\subsection{Research Design}

This research used qualitative research design with phenomenology approach. The research was located in primary school in Kubu Raya district. This location is representing the characteristic of urban and rural adolescence.

\subsection{Participants and Characteristic of Participant}

Researchers were concerned with the credibility and wealth of information, exploring the phenomenon in depth with non-probability sampling [14-15]. Research subjects or participants in this study amounted to 34 people. The number of participants for data collection using the FGD method consisted of three groups. They were 12 persons of adolescents, seven persons of parents, and 15 persons of teacher. Data collection used in-depth interview method consisted of two participants of religious leaders, one from the Ministry of Religious Affairs, and one from the Education Office.

Characteristics of parent participants were in the age range of 26-42 years old, included as Javanese, Malay, and bugis, had variations of gender, age, education, occupation, number of children and had teenagers with varying menarche/semenarche status, some participants had children who have akhil baliq (getting puberty). Mean while, adolescent participants were in the age range of 10-14 years old, which had variations of sex, some teenagers had experienced akhil baliq and others had not experienced it. The characteristics of teacher participants were (1) coming from two public primary schools who were teaching science, religion, and guidance and counseling classes, (2) in the age range of 26-55 years with different gender, (3) the majority education level is S1(undergraduate degree) with the different discipline, (4) having experience in teaching about 5-18 years. The number of participants in this study was 34 people. 


\subsection{Research Instruments and Data Collection Methods}

The data collection techniques used in this research was in-depth interview and focus group discussion (FGD) which referred to the instruments that had been prepared by researchers. Participants were selected by purposive sampling. Data collection was started with collecting secondary data about adolescents and their reproductive health in schools. The researcher coordinated with the education office and the school. Data collection was conducted with the aim of digging deeper information from participants to find and develop school-based reproductive health promotion models. FGD implementation was done based on the group that had been created before, parents, teachers and early adolescents, with the duration of 60-90 minutes. In-depth interviews were conducted separately in accordance with the agreement with the participants. The most important thing was to build trust with participants at the time of data collection. It took a long time to conduct FGDs with early adolescents, and researchers made adjustments in the use of language or reproductive health terms that were poorly understood by them. Meanwhile, when having FGDs with parents, researchers need to encourage the parents to be open in expressing opinions. Most of parents felt embarrassed, inappropriate and taboo to talk about sexual and reproductive health problems in adolescents. Validity and reliability of research referred to 5 categories: descriptive validity, interpretative validity, theoretical validity, generalizability, and evaluative validity [16]. Validation of data was done by using triangulation (data source, methodology, and theory), member checking and auditing.

\subsection{Ethical Consideration}

In general, the ethics of this research met the principles of: beneficence, justice, and informed consent [17]. This research was begun by applying research permission to the Ethics Committee of STIK Muhammadiyah Pontianak. Researchers got ethical clearance and permission to conduct research from related institutions (137/II.I.AU/KET.ETIK/S-1/XII/2017).

Data analysis aimed to explore the relationship between attitudes, behaviors and experiences, developing phenomenon and theory explanations. It was seeing the relationship between the categories or patterns that arise [18]. This study used thematic analysis to find patterns out that may not be found by other researchers.

\section{RESULTS AND ANALYSIS}

\subsection{Information on Reproductive Health}

The results shows teenagers and parents had heard information about reproductive health but the information obtained was incomplete. Reproductive health was understood by parents including the arrival of menstrual and wet dreams as one of the signs of puberty. Like the following narrative from one of the participants:

"The signs of puberty are the growth of Adam's apple in men, the voice is enlarged, the hair grows in the armpit and the chest begins to field and menstruation in women" (FGD with adolescent participants)

"... according to my knowledge of ee .., reproductive health is like puberty, the body changing on child .., like her hips, her breasts, then the arrival of menstruation... Keeping the cleanliness, itching on the genitals ...." (FGD with parent participants)

In addition, the study found that adolescents did not understand about good reproductive organs maintenance, the use of pads, menstrual processes, menstrual problems, vaginal discharge and sexually transmitted infections. But adolescents know that circumcision was done to keep the reproductive organs clean in men and knowing about the disease on reproduction that is related to sexually transmitted diseases. As with one of the following participants:

"Reproductive diseases are such as sexually transmitted diseases," (FGDs with adolescent participants)

Problems arisen were that parents considered information about reproductive health as something taboo to talk about because parents felt embarrassed, and did not have the right words to explain. The difficulty in explaining about reproductive health was due to the lack of understanding about reproduction health as quoted from the following participant statement:

"... never. I'm shy, still young, I'm confused to explain it and I'll explain leter..." (FGD with parent participants) 
The results showed that knowledge about reproductive health in early adolescents (10-14 years) was very limited. This difference in knowledge occurred due to lack of organized access and information exposure about information needed and lack of experience gained by adolescents. While other teenagers knew about reproductive health was linked to sexually transmitted diseases. In line with the results of Indonesia adolescent reproductive health survey (SKRRI) in adolescents aged 15-24 years old mentioned that the knowledge of adolescents about reproductive health was low [5]. Teenagers required more information about reproductive health in accordance with the needs and problems that were often experienced or will be experienced. Reproductive health education programs were essential in preparing reliable information access and empowering them to make wise decisions in using social media [19]. Correct provision of information about reproductive health prevented adolescents' sexual behavior, including sexually transmitted infections [13]. Adolescents relied on families, communities, schools, and health care to learn important skills, to help cope with the pressures they faced during their transition.

\subsection{Problems and Causes of Reproductive Health Problems in Early Adolescence}

The common reproductive health problems identified on young girls were about menstrual and vaginal problems and itching of the genitals. Unlike boys who tend to have no complaints, but exhibit risky behavior, this statement was as conveyed by one of the participants as follows:

"... usually they complain about menstruation up to 2 times in 1 month continuously he also experience vaginal discharge, feel pain during menstruation" (FGD with teacher participant)

The occurrence of loss control and delays in giving understanding opened the chance for the occurrence of free sex behavior resulted in unsafe abortion acts. Parental monitoring and assistance in children in seeking information were needed to be done. The busyness and lack of parental attention had a negative impact on the child on reproductive health issues, such as the expression of participants in the following statement:

"Promiscuity, having boyfriend/girlfriend, too young, and the use of mobile phones Ma'am ... seeing the things that should not be seen, loss control, then they should be given early understanding of what is called as abortion or free sex, shouldn't they?..., the attention of parents is very determining the guidance of his family, where we know now, many parents are busy making a living, either father or mother, so the parents' attention to the child was totally absent, and if parents come or go home late at night, and communication is not good..." (Indepth interview with key participants)

Various factors affected risky behavior in adolescents, such as peer-risk behavior, lack of parental supervision, and parental permissive behavior patterns. In addition, hormonal effects, synchronous biological, psychological and social developments may also contribute to sexual behavior in adolescents. Adolescents who had difficulty in controlling their impulse would trigger the curiosity and want to try. Factors that protect adolescents were including self-control, optimization of family education, parenting in families including strengthening religious foundations, parenting role in giving examples of good behavior, reinforced by good communication between parents and teachers in children's education.

External factors such as social environment, juvenile life style, multimedia exposure, and peers were also very influential on adolescent behavior. Media or internet sites that can be accessed easily also influenced adolescents' behavior. The media had both positive and negative impacts on adolescent knowledge, beliefs, and attitudes about reproductive health. Models of risk behavior in adolescents consisted of predisposing factors and protective factors that each had endogenous and exogenous factors. In predisposing factors, endogenous factors consisted of cognitive immaturity, depression, low self-esteem, gender, genetics, views of values, hormonal effects and the synchronization of biological, psychological and social developments. Exogenous factors consisted of risky behavior from peers, lack of parental supervision, school failure, poverty, rejection of the social environment, parental involvement in risky behavior, and parental permissive parenting. Protective factors consisted of endogenous factors that included normal affective conditions, complete self-esteem, academic achievement, religious values, and maturity of cognitive development. Exogenous factors included academic achievement, whole family, parental support, friend's denunciation of risky behavior, religious activity, involvement in school activities and authoritarian parenting. Precipitation factors consisted of peers who initiate risky behavior, social pressure, school transition, family problems, the use of drugs, and susceptibility [20]. 


\subsection{Teenage Information Needs about Reproductive Health}

Teenagers needed a lot of true, accurate and openly information about the changes in their selves when the akhil baliq. The study found that adolescents also needed information about menstruation, menstrual process, white discharge problems experienced, sexually transmitted infection, body shape changing during puberty and reproductive organ care such as male circumcision. This was conveyed by the following adolescent participants:

".. White discharge problems Ma'am .... .. What the menstruation cycle is, why it can be irregular, what suitable material for underwear made from and the name and the illness of the organ .." (FGD with adolescent participants)

"... Why girls have menstruation, and why boys have Adam's apple?" (FGD with teenage participants)

Adolescents needed information and counseling about reproductive health faced. Information needed by early adolescents were about menstrual problems, menstrual cycles, wet dreams, vaginal discharge, causes and effects of white discharge, anatomy and physiology of reproductive organs, and hygiene maintenance of reproductive organs. Besides that, the problem of teenagers' socialization and sexually transmitted infections were also included. In addition to parents, teachers played a role in improving adolescents' reproductive health. Teens were at risk for reproductive health problems and needed serious attention [1]. Health problems in early adolescence (10-14 years) included problems when teenagers experience menarche. The most reaction commonly reported was $67 \%$ of female adolescent respondents were shocked, weeping and afraid of what they were experiencing [19].

\subsection{Sources of Information and Friends for Discussion about Reproductive Health}

Sources of information and friends for discussion about reproductive health were varying widely. Source of information about puberty of teen girls' was parents, especially mothers and friends, while boys preferred friends as friends for discussion. Parents could be an unfavorable source of information if not supported by an understanding of knowledge about reproductive health, so that adolescents did not get accurate information. In this study found some participants of the female gender who have not experienced akhil baliq yet conveyed that the source of information and friends for discussion preferred for them was parents, especially mothers, and other family members, especially teenagers who had older siblings or aunts who lived in one house, besides with parents the other choice is discussing with teachers and friends. For teenagers who had experienced akhil baliq also preferred friends and other family members like brother and aunt to as sources of information other than mothers. For male participation, their information resources and discussion friends about reproductive health were friends and teachers, although there were also participants who declared the source of information and discussion friends are parents and friends. Audiovisual media such as television were also very popular among teens to fill leisure time and entertainment facilities, but not necessarily provide events specifically for reproductive health information for adolescents. Another source of information was from multimedia mobile phones and social media that could be accessed easily on the internet. Like the statement of one of the following teacher participants:

"... then for kids nowdays, emmm .. they seem to know more, maybe emm .. because there are facilities like mobile phone, well, it's only a personal thinking, internet, so they are rather free. There are also the same parents, but sometimes parents will not explain ... "(FGD with teacher participants)

\subsection{Model of School-based Reproductive Health Promotion Program}

Some of the reasons for the promotion of reproductive health can be in form of school-based are because it is efficient and cost-effective [19]. The use of various teaching methods was designed to increase active student participation and for personalization. Programs designed to reduce risky sexual behavior, so the curriculum developed for the program should use theory and research on the factors that influence sexual behavior. The effectiveness in the sexual education implementation becomes very important by incorporating the values of culture and religion, in order to form morals of adolescence. School-based reproductive health had proven to be very effective in improving knowledge and improving attitudes among adolescents, and enabling them to know accurately in identifying signs of puberty, to understand how sexually transmitted infections were transmitted.

Sexuality education did not encourage teenagers to engage in free sex, while providing reproductive health information provided teens with opportunities to explore their values and attitudes while building skills for making decisions, communicating with others, and reducing the risk of health problems. Schoolbased reproductive health promotion programs had full support from students, parents and teachers. All parents agreed if the program was implemented in school. All adolescents agreed if the school carried out 
a reproductive health promotion program. There is difference of opinion among adolescents about the implementation of the program. Some teenagers wanted the program was conducted after school hours or in special meetings. Some others teenagers wanted the program to be carried out during school hours and made into one independent subject. Providing reproductive health education in schools was an effective way to reach adolescents. School-based reproductive health promotion policies are recommended for improvement of reproductive health in adolescents. Such support can be seen in the following participant statements:

"It is really needed Ma'am... we agree." (FGD with teacher participants)

1) Extracurricular Activities of Reproductive Health

Implementation of reproductive health promotion programs in schools could be done either through formal curricula or extracurricular activities given in early adolescence. The recommended program model was the extracurricular program as an additional school lesson.

"... it is true, in extracurricular, for additional, therefore it needs an extra hour, well it needs extracurricular, can be in school or other place" (indepth interview with key participants)

2) Management of Participants

Reproductive health promotion programs were effective when aimed at the early stages of development, especially for those who were not sexually active. In this study the program was aimed at primary school adolescents aged 10-14 years and had not experienced akhil baliq. The results of this study found that, in the management of participants, some participants wanted male and female students were in one class during the learning activities, as quoted from the statement of one of the following participants:

"... I think it should be both Ma'am, combined it, it is more effective, do not have to be separated, so let them know. It's okay for men to know about women problems, and instead "(FGD with participants teacher)

In fact, grouping participants according to the same gender, for some or all programs had proven its effectiveness. Management of participants could be done separately or combined with various considerations. Boys and girls could be combined in one class with separate seating arrangements between girls and boys.

\section{3) Location and Execution Time}

The results of this study found and recommended several locations for the implementation of the program. Selection of places was adjusted to the material needs and objectives of the activity. Adolescents stated the length of time in a single meeting was around two hours of lesson once a week. Meanwhile, teachers argued that the time of execution of activities during a session was two to three hours using various methods and media so as not to be boring.

"... I think, for now, it is better for two lessons hours/meeting or about 100 minutes" (FGD with teacher participants)

The results of this study recommended that the program should be implemented for 12 meetings, including pretest and post-test (1 meeting per week) in extracurricular form. The time of each session range was from one to two hours (with a calculation of 50 minutes per hour). The length of time each session was adapted to the materials, methods and media in the learning process.

4) Methods and Media

The effectiveness of various learning strategies was adjusted to the needs and aims to optimize the learning process, so that the objectives of the program can be achieved. Methods and media chosen are based on age and development. The methods that might be used include lectures, discussions, frequently asked questions, composing puzzles, viewing drawings, role plays, and assignments. The use of learning methods in a variety of learning process, could improve adolescent knowledge about reproductive health could also make the atmosphere more enjoyable learning process. Some alternative methods like the following participant statement:

"... well, firstly they are introduced to the material such as explanation by using LCD projector, then with audiovisual. For me, it is more effective and they result is also more appropriate ..." (FGD with teacher participants)

IJPHS Vol. 7, No. 2, June 2018: $81-90$ 
"... The method in the suggested program is by playing, giving theory to the class. It is also a combination of theory and video impressions as well as pictures "(FGD with teacher, Do 31 years)

"... Using pictures, let the children be interested and not bored" (FGD with teacher participants)

Types of media used included audiovisual and visual form of interesting pictures and modules/textbooks, methods of group discussion, experimentation/demonstration, role-play, visual aids, brainstorming, storytelling, and audiovisual. Previous research had shown that one of the most effective ways to improve child and parent communication about sexuality was by providing homework when the students had to discuss selected topics with parents or other trusted adults. If teachers and parents supported each other in applying structured teaching, the possibility of adolescent personal growth tends to be much better. Learning objectives and methods were adjusted to the student's age and culture. Interventions needed to be developed by simplifying the subject matter, introducing alternative teaching methods, improving teachers' knowledge and understanding [21].

5) Material

The recommended material were such as puberty material for men and women, intercourse between the opposite sex after akhil baliq, reproductive organ maintenance, self-control, use of underwear and consequently if not clean, and hazards that may occur. Like the statement of one of the following participants:

"... Women have enlarged her breasts, then sighed by menstruation, while for man, they had wet dream .... Meaning you guys in relation to the opposite sex should be limited and careful, normal feelings if likes the opposite sex, there is interest but must be controlled ... then cleanliness and the dangers also " (FGD with teacher participants)

The recommended material might be inspired by wrong sexual behavior. The material was given by the teacher and worked with the experts, such as the following participants:

"... The material can be like its adverse effects, its illnesses, or the misuse of this reproduction" (indepth interview with key participants)

Provision of reproductive health information should be adjusted to the age and stages of adolescent development and provided gradually. Some materials could improve adolescent competence according to WHO recommendations, such as adolescent growth and development, adolescent body changes toward puberty. In addition, sexuality and gender, sexual attitudes and behavior, menstruation, menstrual hygiene, and menstrual problems, including sexually transmitted infections also could be chosen [22].

\section{6) Program Resources}

The explanations should be given by experts based on their specification about reproductive health. As one of the following participants says:

"... It is better if the students are explained by the experts in their field. If parents may not know much about it, but if those in the health field, who take care of reproductive health that goes into school programs, will be more clear" (indepth interview with key participants)

The openness and motivation of teachers to discuss about reproductive health issues in the classroom was crucial. A female teacher was specially trained. Teacher training was the key to the success of school-based reproductive health education program because it could influence knowledge, attitude, and motivation to teach. Provision of reproductive health information in schools could be done by teachers, especially religious and science. Teachers should understand about reproductive health problems in adolescents, although interviews and observational findings found that in reality, teachers had less control over reproductive health problems in depth. Strengthen teacher's knowledge according to child development phase was required.

"... We want religious teachers to also participate in it, of course there should be reproductive health in religious lessons, because on that ages, they have already experienced transition, the transition to puberty. Well that's the case so they really have to be true-right controlled, well now we have done the effort, and we have told to all religious teachers. We have already told them every 
time, since long time, so it's not only this year ... biology teachers then religious teachers, science teacher "(indepth interview with key participants)

Parents also argued that in beside teachers, the other right resource persons in this program are health practitioners or people who are experts in their field. With collaboration between teachers and health practitioners, it was expected that information on reproduction health that be obtained by teenagers was more comprehensive. The statement was quoted by the participants as follows:

"... simultaneously, simultaneously with the collaboration between teachers and health workers" (FGD with parent participants)

"... I think if it was collaboration, it means that there are experts who can explain then there are teachers also" (FGD with parent participant)

Teachers are part of the school structure, known and trusted by the community and establish good relationships with students. Teachers can integrate the message of reproductive health and sexuality into the subjects. Based on the findings of this qualitative study and the evidence base or previous studies, this study recommended that resource persons in the program implementation are from reproductive health practitioners and trained teachers.

\subsection{Recommendation of School-based Reproductive Health Promotion with "Extracurricular" Approach of Reproductive Health on Early Adolescents in School}

Sex education did not encourage adolescents to engage in free sex, while providing reproductive health information and provided teens with opportunities to explore their values and attitudes while building skills to make decisions, communicate with others, and reduce the risk of health problems [22], [19]. School-based reproduction health promotion had proven to be very effective in improving knowledge and improving attitudes among adolescents. Let them know accurately to identify signs of puberty, and understand how sexually transmitted diseases spread [23]. Schools were selected as a site for interventions related to sexuality and reproductive health [10]. School-based reproductive health promotion policies were recommended for improvement of reproductive health in adolescents [19]. Sexual and reproductive health education in adolescents could be provided through formal or informal channels based on the goal of equipping knowledge, skills and a sense of responsibility for human reproductive function [9]. The implementation of reproductive health promotion programs in schools could be done either through formal curriculum or extracurricular activities given in early adolescence [9], [19]. An effective curriculum was structured or modified to include all the topics needed by teenagers, teachers and health workers [8].

The reproductive health promotion program was effective if it was aimed at an early stage of development, especially for those who were not sexually active [24]. In the implementation of the effects program was proven to be better and more effective if the program targets were early adolescent or early adolescents [10]. Providing education about reproductive health could educate children about healthy sexuality and a very important way to protect them from physical and sexual abuse, prevent sexual harassment and to increase the likelihood of reporting in the event of sexual violence [11], [19].

The theory used for program planning was intervention mapping. There were 6 basic steps that could be spelled out as follows: first perform an assessment or needs analysis, second, create a matrix based on determinants of behavior and environmental conditions. Third, choose the theory-based intervention method and practical strategy. Fourth, translate the methods and strategies into an organized program. Fifth, plan an adoption, implementation, and sustainability of the program and the sixth, produce an evaluation plan. The adolescent reproductive health extracurricular program was developed using a mapping intervention approach as a reference to the development of theories on school-based reproductive health promotion programs [25].

Qualitative research conducted, aimed to find the model or pattern of programs to be applied. Explanation about intervention mapping steps in this study were: first stage intervention mapping was about the objective of the program, which was to explore and clarify feelings and establish positive values and attitudes and information needs on reproductive health to promote and maintain behavior that was possible to reduce risky behavior in reproductive health. The second intervention mapping was by making a matrix based on determinants of behavior and environmental conditions. Researchers identified factors that influenced early adolescent behavior on reproductive health and alternative solutions to address the problem. Furthermore, the third stage of intervention mapping was about the foundation of theory and strategy. At this stage, researchers identified it theoretically and evidence-based interventions that had been effective. The intervention was conducted in the form of reproductive health promotion programs that were packed in extracurricular form of reproductive health. The fourth stage of the intervention mapping was program 
design, started with a qualitative study to explore the model of the program to be developed. In addition to the findings of qualitative research that had been done, in the development of the program researchers also referred to the theories and evidence base of previous research. The fifth phase of intervention mapping was about planning the adoption and implementation program. Implementing or developing the program required collaboration between researchers, school teachers, parents and adolescents in program development. The development of a health promotion program was based on the theory and evidence base and the strategy adopted. The researcher developed a program model consisting of: 1) formulating the competence to be mastered in the implementation of the reproduction health promotion program on the early adolescents (age 10-14 years) in primary school students, 2) designing, compiling the standard of reproductive health extracurricular competence as well as developing the model and printing program modules for students and facilitators; 3) designing and preparing the media used according to recommendations obtained from the first stage of research, evidence base and theories. The prepared media include: student learning module, teacher module, projector slide, props, role play property, video, camera, puzzle of reproduction organ image and, 4) developing learning strategy in the form of interactive methods. The methods used are: lecturing, brainstorming, small group discussions, questioning, filling quizzes in worksheets, role-play, take home assignment that involving parents, and demonstrations/simulations. In the 6th stage intervention mapping: Evaluation of developed outcomes was measured by the resulted pre-test and post-test and the effects of the implemented program. In addition, in modeling the intervention, it referred to the Template for Intervention Description and Replication (TIDIeR) Checklist. TIDIeR provided information related to the description of the intervention. TIDIeR included the various components that would be accommodated in the intervention model.

This study recommended a program called extracurricular reproductive health with the slogan "greeting adolescence with healthy and obedient". This school-based program was aimed at early adolescents (10-14 years old), who had not experienced akhil baliq and studied at primary school. The program aimed to improve knowledge, shape attitudes and positive behavior of adolescents towards reproductive health with a religious approach. The researcher developed the basic competencies that must be possessed by early adolescents (10-14 years) and being developed in a standard of competence that described the knowledge, affective and skill that must be possessed based on the results of research and theories. The increasing of knowledge and understanding of adolescent about reproductive health during pre-puberty would equip adolescent to continue to the development process with full of responsibility. Participants would have positive values and attitudes and behaviors on reproductive health.

The reproductive health extracurricular program was given 12 sessions including pre- test and posttest, with duration 100 minutes at each session. The learning program was arranged in a syllabus, involving resource persons from health practitioner, teachers and parents in order to improve the communication of participants and parents. In this program, training on teachers involved in reproductive health programs was conducted before. Besides that, parents were involved in helping students to do homework provided by the facilitator at home. Teacher training was very important; all teachers must have knowledge, skills, character and quality. Components that possibly used in the development of reproductive health promotion were curriculum, especially cognitive, affective and behavioral domains. An effective curriculum was structured to include all the topics needed by teenagers, teachers, and health workers [8].

Program was designed with methods and learning media that was fun for teenagers, so they did not feel bored during the program. To improve the quality of learning, every adolescent was equipped with training module as well as facilitator and resource person. Methods in the program were lecturing, group discussions, brainstorming, and role-play, story-telling, audiovisual and providing homework to students. Media in the program were modules for students, teachers, projector slide, video, camera, property for role play, picture puzzle of reproductive organs, and property about sexual and reproductive health messages. Program material included akhil baliq, menstruation, and maintenance of reproductive organs. The implementation of activities was conducted after school, by choosing places that were conducive. Male and female students were made into one class, but with separated seats when the program was implemented

\section{CONCLUSION}

This study recommends a program about "Extracurricular School based of reproductive health for early adolescents who experience before Akhil Baliq. This study also develop basic of competension which must be owned in the health competency standard of reproductive health for early adolescents in school aged 10-14 years old. Competence development includes knowledge, affective and skills in reproductive health. The program is done outside of school by involving teachers, parents and health workers. For increase quality of study, this research used a method notice adolescents growth and development. Every adolescents, facilitator, and keynote speakers in this study given a training modul. 


\section{ACKNOWLEDGEMENTS}

We thank to Educations authorities of Kubu Raya district, UPTD Rasau Jaya sub-district, Participants of this study, and Institutte of Nursing Muhammadiyah Pontianak as research funders.

\section{REFERENCES}

[1] Hindin, Michelle, J., Sigurdson, C. C., Jane F. B., "Setting research priorities for adolescent sexual and reproductive health in low and middle-income countries", Bulletin of the World Health Organization. 2013; 91; 10-18, doi.10.2471/BLT.12.107565, 2013.

[2] Nurohmah, A., "The importance of early reproductive health education in the family", Center for Gender Studies of Universitas Islam Indonesia-Kubu Raya Indonesian Islamic University, 2013.

[3] Research and Population Development Center (BKKBN), "Indonesia reproductive health survey for adolescent 2007: Summary of result", https://digilib.bkkbn.go.id/index.php?p=show_detail\&id=36165\&keywords=, accessed Desember 2012, 2007

[4] Research and Population Development Center-BKKBN. "The profile assessment of the adolescent population (10-24 years), there with teenagers". Series I No. 6/Pusdu-BKKBN/December 2011, 2011.

[5] BPS, BKKBN, Department of Health, Macro International Inc. "Reproductive health of Indonesian adolescents 2002-2003", Jakarta, 2008.

[6] UNICEF, "Indonesia annual report" 2012. UNICEF Indonesia, 2012.

[7] Ministry of Health Research and Development RI. "National Report on Basic Health Research 2010". (http://www.diskes.baliprov.go.id/files/subdomain/diskes/Januari\%202015/RISKESDAS\%202010.pdf), accessed May 2016)

[8] UNFPA, "Towards realizing the full potential of adolescents and youth; UNFPA strategy on adolescents and youth". (http://www.un.org/Docs/journal/asp/ws.asp?m=A/65/L.77 accessed November 2012 ), 2012.

[9] WHO, "The sexual and reproductive health of younger adolescents research issues in developing countries". Printed by the WHO Document Production Services, Geneva, Switzerland, 2011.

[10] Aarø. L. E., Flisher. A. J., Kaaya. S., Onya. H., Fuglesang. M., Klepp. K. I, Schaalma, H., "Promoting sexual and reproductive health in early adolescence in south africa and tanzania: development of a theory-and evidence-based intervention programme". Scandinavian Journal of Public Health, 2005 ISSN 1403-4948 print/ISSN 1651-1905 online/05/010001-9 \# 2005 Taylor \& Francis Group Ltd DOI: 10.1080/14034940510032356, 2005.

[11] WHO, “Annual technical report 2011". World Health Organization, Geneva, Switzerland, 2012 https://www.bps.go.id/linkTabelStatis/view/id/1810

[12] O' Rourke, K., "Time for a national sexual \& reproductive health strategy for australia", PHAA, SH\&FPA and ARHA, 2008

[13] Dailard, C. "Sex education: politicians, parents, teacher, and teens". The Guttmacher Report on Public policy, 2001

[14] Creswell, J. W. "Educational research: planing, conduction and evaluating quantitative dan qualitative research". Lincoln University of Nebraska, 2008

[15] Raco, J. R. "Qualitative research methods; types, characteristics and advantages". Jakarta. PT Gramedia Widiasarana Indonesia, 2010

[16] Thomson, S.B. (2011). Qualitatif Research: Validity. JOAAG, Vol.6 No.1.

[17] Dodd, T.J. (2003). "A guide to research ethics". (http://www.lib.uconn.edu/DoddCenter/ASC/dodphot1.htm, accessed, November 2013), 2003.

[18] Arneson, H., Ekberg, K. "Evaluation of empowerment processes in a workplace health promotion intervention based on learning in Sweden". Health Promotion International, Vol. 20 No. 4, 2005.

[19] Wahba, Fahimi, R. F. "The need for reproductive health education in schools in egypt". (http://www.prb.org, accessed February 2014), 2012.

[20] Igra, V., Irwin, C. E. "Risk and risk taking in adolescent. Edited by. Linstrom, B., Spencer, N. Social Pediatrics. Oxford University Press, 1995.

[21] Plummer, M. L., Wight, D., Wamoyi, J., Nyalali, K., Ingall, T., Mshana, G,. Shigongo, Z. S., Obasi, A. I. N., and Ross, D. A. "Are schools a good setting for adolescent sexual health promotion in rural africa? a qualitative assessment from tanzania. Health Education Research Vol.22 no.4.Pages 483-499, 2007.

[22] UNAIDS, UNFPA, UNICEF, WHO. "International technical guidance on sexuality education an evidenceinformed approach for schools, teachers and health educators". Volume 1 The rationale for sexuality education. (http://unesdoc.unesco.org/images/0018/001832/183281e.pdf, accessed, Desember 2017), 2009.

[23] Tawfik, El-Sharkawy, O. G., Abdelbaqy, M. A., Hanafy, S. A., Malek, A., Kharboush, I., Ismail, H. M. "Schoolbased reproductive health education among adolescent girls in alexandria, egypt. (http://www.prb.org, accessed February 2014), 2013.

[24] WHO "Promoting the sexual and reproductive health of adolescents. WHO (www.who.int/reproductivehealth/topics/adolescence/en/index.html, access November 2013), 2010.

[25] Bartholomew Bartholomew, K., Parcel, G. S., Kok, G., Gottlieb, N. H. " Planning health promotion programs an intervention mapping approach”. Jossey Bass A Whiley Imprint, 2006. 